been extremely difficult, if not impossible. In this outbreak, receipt of intermittent IV therapy was a possible determinant for increased BSI risk; because this form of therapy is common among outpatients receiving home IV therapy, an urgent need exists to develop BSI surveillance systems for such patients. Paradoxically, it may be outpatients receiving "low-intensity" intermittent IV therapy via CVCs who are at the greatest risk for BSIs associated with needleless devices. Our results suggest that intermittent intravenous therapy or flushing practices may be important determinants of BSI risk associated with some needleless devices and again emphasize the need to monitor infection rates closely after the introduction of any new medical device.

\section{REFERENCES}

1. Benson JS. FDA Safety Alert: Needlestick and Other Risks From Hypodermic Needles on Secondary I.V. Administration Sets-Piggyback and Intermittent I.V. Rockville, MD: Food and Drug Administration; 1992 Letter to all US physicians.

2. Skolnick R, LaRocca J, Barba D, Paicieus L. Evaluation and implementation of a needleless intravenous system: making needlesticks a needless problem. Am I Infect Control 1993·21:39-41.

3. Ippolito G, De Carli G, Puro V, Petrosillo N, Arici C, Bertucci R, et al. Device specific risk of needlestick injury in Italian health care workers. JAMA 1994;272:607-610.

4. Danzig LE, Short LJ, Collins K, Mahoney M, Sepe S, Bland L, et al. Bloodstream infections associated with a needleless intravenous infusion system in patients receiving home infusion therapy. JAMA 1995;273:1862-1864.

5. Kellerman S, Shay DK, Howard J, Goes C, Feusner J, Rosenberg J, et al. Bloodstream infections in home infusion patients: the influence of race and needleless intravascular access devices. J Pediatr 1996;129:711-717.

6. Do A, Banerjee J, Ray B, Barnett B, Pham M, Ball L, et al. Evaluation of the role of needleless devices in bloodstream infection in home infusion therapy. Presented at the 36th Interscience Conference on Antimicrobial Agents and Chemotherapy; September 17, 1996; New Orleans, LA. Abstract J61.

7. Garner JS, Jarvis WR, Emori TG, Horan TC, Hughes JM. CDC definitions for nosocomial infections, 1988. Am J Infect Control 1988;16:128140.

8. Pollack MM, Ruttimann UE, Getson PR. Pediatric risk of mortality (PRISM) score. Crit Care Med 1988;16:1110-1116.

9. Pearson ML, the Hospital Infection Control Practice Advisory Committee. Guideline for prevention of intravascular device-related infections. Infect Control Hosp Epidemiol 1996;17:438-473.

10. Daumal M, Daumal F, Piot C, Manoury B, Colpart E. One year survey of needleless intravenous access system in ICU. Presented at the 36th Interscience Conference on Antimicrobial Agents and Chemotherapy; September 17, 1996; New Orleans, LA. Abstract J62.

\title{
Multidrug-Resistant Pneumococcal Pneumonia in a Nursing Home
}

Gina Pugliese, RN, MS Martin S. Favero, PhD

An outbreak of multidrug-resistant pneumococcal pneumonia was reported recently among the residents of a nursing home in rural Oklahoma. Nasopharyngeal swabs for culture were obtained from residents and employees, and Streptococcus pneumoniae isolates were serotyped and compared by pulsed-field gel electrophoresis (PFGE). A retrospective cohort study was conducted to identify factors associated with colonization and disease.

Pneumonia developed in 11 (13\%) of 84 residents, 3 of whom died. Multidrug resistant $S$ pneumoniae, serotype $23 \mathrm{~F}$, was isolated from blood and sputum from 7
(64\%) of the 11 residents with pneumonia and from nasopharygeal specimens from $17(23 \%)$ of the 74 residents tested and 2 (3\%) of the 69 employees tested. All the serotype-23F isolates were identical according to PFGE. Recent use of antibiotics was associated with both colonization and disease. Only three residents (4\%) had received pneumococcal vaccine. After residents received pneumococcal vaccine and prophylactic antibiotics, there were no additional cases of pneumonia, and carriage rates decreased substantially.

Outbreaks of pneumococcal disease are uncommon and have occurred mainly in institutional settings. Epidemic, invasive, drug-resistant pneumococcal disease has not been seen among adults in the
United States. In this outbreak, a single pneumococcal strain was disseminated among the residents and employees of a nursing home. The high prevalence of colonization with a virulent organism in an unvaccinated population contributed to the high attack rate. Clusters of pneumococcal disease may be underrecognized in nursing homes, and wider use of pneumococcal vaccine is important to prevent institutional outbreaks of drug-resistant $S$ pneumoniae infection.

FROM: Nuorti JP, Butler JC, Crutcher JM, Guevara R, Welch D, Holder P, et al. An outbreak of multidrug-resistant pneumococcal pneumonia and bacteremia among unvaccinated nursing home residents. N Engl J Med 1998;338:1861-1868. 